Удк 316.346.32-053.9

\title{
СТРАТЕГИИ ЖИЗНЕСТОЙКОСТИ ПОЖИЛЫХ ЛЮДЕЙ
}

\author{
Иванкина Любовь Ивановна, \\ ivankina@tpu.ru \\ Аникина Екатерина Алексеевна, \\ anikinaea@tpu.ru \\ Клемашева Елена Игоревна, \\ eik15@tpu.ru \\ Касати Фабио, \\ casati@tpu.ru \\ Национальный исследовательский Томский политехнический университет, \\ Россия, 634050, Томск, пр. Ленина, 30

\begin{abstract}
Иванкина Любовь Ивановна, доктор философских наук, профессор, ведущий научный сотрудник Международной научно-образовательной лаборатории технологий улучшения благополучия пожилых людей Национального исследовательского Томского политехнического университета.
\end{abstract}

Аникина Екатерина Алексеевна, кандидат экономических наук, доцент Школы инженерного предпринимательства Национального исследовательского Томского политехнического университета.

Клемашева Елена Игоревна, кандидат экономических наук, доцент отделения социальногуманитарных наук Школы базовой инженерной подготовки, научный сотрудник Международной научно-образовательной лаборатории технологий улучшения благополучия пожилых людей Национального исследовательского Томского политехнического университета.

Касати Фабио, Ph.D., ведущий научный сотрудник Международной научно-образовательной лаборатории технологий улучшения благополучия пожилых людей Национального исследовательского Томского политехнического университета.

Актуальность проблемы жизнестойкости людей пожилого возраста обусловлена научнопрактическим интересом поиска моделей и способов развития компенсаторных возможностей человека на этапе позднего онтогенеза. Современный подход к вопросам старения меняет пессимистичный взгляд на данный период жизни человека как финитный, завершающий, связанный с увяданием и угасанием жизненных функций, на оптимистичный, рассматривающий период позднего онтогенеза как этап продолжающегося развития человека. Цель работы - выявить особенности и основные виды стратегий жизнестойкости пожилых людей. Проведен анализ данных социологического опроса, позволивший выявить уровень жизнестойкости на основе показателей, значимых для измерения и контроля основных аспектов благополучия пожилых людей - удовлетворенность жизнью, вовлеченность в социальные отношения, ощущение счастья, уверенность в завтрашнем дне. Методика исследования основана на операционализации понятий «жизнестойкость» и «неравенство», что позволило выделить источники неравенства в аспекте ментальных практик мыслей, убеждений, представлений о собственной роли в обеспечении благополучия. Данный подход обусловлен прежде всего психологической природой феномена жизнестойкости как особого переживания, гарантирующего человеку способность действовать в сложных, неопределенных ситуациях максимально эффективно. Результаты: обоснованы параметры дифференциации стратегий жизнестойкости людей пожилого возраста, выявлена специфика и их виды в период позднего онтогенеза. Анализ данных социологического опроса пожилых людей позволил выявить ресурсы жизнестойкости, к которым отнесены благополучие семьи и близких людей и возможность принимать решения и реализовывать намеченные планы. Выявлены параметры социальной субъектности, препятствующие поддержанию качества жизни и повышению жизнестойкости людей в 
пожилом возрасте, - это перекладывание ответственности на других при закрепившейся позиции «мне должны».

Ключевые слова: Жизнестойкость, люди пожилого возраста, стратегия жизни, стратегия жизнестойкости, жизненная позиция, субъективное благополучие.

В самой категории «жизнестойкость» содержится главный смысл понятия - стойкость жизни. По определению С. Мадди, одного из первых исследователей природы жизнестойкости и автора самого термина, жизнестойкость означает системное образование личности, помогающее человеку преодолевать жизненные затруднения [1]. В жизнестойкости как сложном когнитивно-аффективном феномене выделяется внутренняя структурированность, фиксируемая рядом измерений, позволяющих индивиду выявлять восприятие себя в повседневных жизненных практиках как успешного или неуспешного. То, как человек справляется с возникающими препятствиями, формирует его систему убеждений, приоритетов, ценностей, помогающих преодолевать препятствия и сохранять способность к принятию ситуации и ее изменению в ближайшей и отдаленной перспективе.

Доминирующие идеи, ценности, установки, задающие индивидуальноспецифичные координаты значимого для человека, выступают фактором, регулирующим процесс жизнестойкости. С осмысленностью собственной жизни связывают жизнестойкость многие зарубежные (М. Аргайл, В. Франкл $[2,3]$, и др.) и отечественные (Г.И. Борисов, Т.Е. Левицкая, Э.Ф. Зеер, Э.Э. Сыманюк, С.Е. Кольман, М.А. Курилович, В.Е., Е.В. Купченко, Елькина, О.В. Супрунова [4-9] и др.) авторы, определяющие жизнестойкость как систему убеждений человека о мире и своем месте в нем. В этом случае установки сознания на восприятие происходящего, указывая на уровень жизнестойкости человека, фиксируют его взгляд на мир - оптимистичный или пессимистичный. Оптимистично настроенный человек верит в свою способность справляться с возникающими препятствиями и выходить из них с минимальными потерями.

Ценностно-мотивационная сфера индивида является основанием взаимообусловливания субъективного благополучия и жизнестойкости, проявляясь в прямой зависимости уровней жизнестойкости и субъективного благополучия. Чем выше уровень жизнестойкости человека, тем выше уровень его субьективного благополучия, и наоборот, чем ниже уровень жизнестойкости, тем меньше уровень субъективного благополучия. Данная взаимосвязь была подтверждена в исследованиях Е.В. Бородкиной [10], выявившей, что людям с высоким уровнем субъективного благополучия характерны вовлеченность в происходящее, уверенность в завтрашнем дне, убежденность в возможности контролировать свою жизнь, что соответствует ранее полученным С. Мадди [11] результатам относительно параметров жизнестойкости.

Согласно модели психосоциальных этапов развития личности (стадии жизни) Э. Эриксона [12], рассматривающей развитие в системе социальных отношений, период выхода на пенсию совпадает с седьмой фазой - фазой средней зрелости, включающей широкий хронологический интервал (возраст 25-65 лет) и восьмой фазой развития (после 65 лет), получившей название поздней зрелости. Период седьмой фазы характеризуется стремлением к продуктивности, созидательности (генеративности), проявляющейся в заинтересованности в жизни в целом, и то, как человек решает данные задачи, формирует его продуктивность жизни, итоги которой подводятся им на завершающей фазе поздней зрелости. В зрелом возрасте вследствие ранее пройденных этапов личностного становления и развития жизнестойкость приобретает устойчивые свойства характера личности и жизненной позиции человека. 
Значимость жизнестойкости на разных этапах жизненного пути человека имеет универсальную составляющую, заключающуюся в личностных особенностях переживаний и действий человека в ответ на возникающие трудности, и является системным качеством жизненной позиции человека (активный-пассивный, оптимистичныйпессимистичный, уверенный-неуверенный, адаптивный-дезадаптивный), что оказывает прямое воздействие на формирование стиля действий и переживаний устойчивого реагирования, закрепившегося в стратегию, которая проявляется в типичных ситуациях, отражая качество этой реакции на уровне автоматизмов.

В случае конструктивного прохождения предыдущих стадий, в соответствии с концепцией стадий развития личности Э. Эриксона, к восьмой фазе человек приобретает опыт переживания трудностей с высокой степенью уверенности в собственных силах, в том, что справится с любыми испытаниями, принимая реальность такой, какой она является. Люди, реагирующие подобным образом, характеризуются высоким уровнем жизнестойкости и удовлетворенности собственной жизнью, и, напротив, непринятие собственной жизни, неудовлетворенность тем, что человек имеет на данный момент времени, мрачное восприятие будущего, опасение не справиться самостоятельно с трудностями формируют низкий уровень жизнестойкости, неудовлетворенность реальностью и пассивное ожидание изменений к лучшему, в том числе необоснованные надежды на помощь государства.

По содержанию реагирования на затруднительные ситуации люди делятся на жизнестойких, преуспевающих и нежизнестойких, пострадавших. В данном контексте жизнестойкость отражает субъективное благополучие человека и связана с мотивацией и практикой преобразования стрессогенных жизненных событий, уровнем самоэффективности и удовлетворенности собственной жизнью.

Стратегии жизнестойкости существенно варьируются в зависимости от степени актуальности ситуации и необходимости ответа на ее вызов. Требования внешнего мира воспринимаются человеком не как угроза, а как вызов, приглашение к риску и росту. В постоянной динамике выявления вызовов и подтягивания к ним соответствующих навыков удовлетворяется базовая потребность в трансцендировании, или выходе за пределы известного, в новые пространства навыков, способностей, умений. Данные изменения связаны с процессом актуализации развития индивидуальности человека. В результате трансцендирования происходят существенные изменения в ценностносмысловой сфере личности. Умение замечать вызовы ситуации и принимать их - глубоко индивидуальное свойство.

Гипотезой исследования является утверждение о том, что высокий уровень жизнестойкости в пожилом возрасте позволяет конструктивно справляться с трудностями, не снижая качества субъективного благополучия, достигнутого ранее на предыдущих этапах жизни. Эмпирическое подтверждение данного предположения проведено с использованием результатов социологического опроса пожилых людей, проведенного в Томской области в 2017 гг. в рамках реализации научного проекта «Оценка и улучшение социального, экономического и эмоционального благополучия пожилых людей» Международной научно-образовательной лаборатории технологий улучшения благолучия людей пожилого возраста при Томском политехническом университете. В анкету опроса 2017 г. была включена шкала UCLA Loneliness Scale Д. Рассела, Л.Э. Пепло, М.Л. Фергюсона (1980), позволившая зафиксировать переживания на момент опроса (в течение недели) и их устойчивость, исходя из опыта имевших в прошлом переживаний. В социологическом опросе принимали участие пожилые люди в возрасте от 55 лет и старше, проживающие на территории г. Томска и Томской области. 
Всего в опросе участвовало 400 чел. Доверительная вероятность составляет 95 \%, что соответствует практике проведения социологических исследований в России и международном сообществе. Ошибка выборки при заданном ее размере составляет 4,89 \%.

В выявлении стратегий жизнестойкости применим понятие стратегии жизни, что позволяет рассматривать жизнестойкость комплексно как процессуальный, содержательный и результирующий феномен. Выбор жизненной стратегии человеком происходит как осознанно, так и в первую очередь бессознательно, автоматически, на основе тех результатов, которые получает человек, решая свои жизненные задачи. Под стратегией жизни будем понимать формирующуюся в жизненных практиках устойчивую тенденцию принимать решения по согласованию необходимого и реально достижимого.

Действуя, человек реализует свои намерения во внутреннем и внешнем плане жизни, каждый из которых, в свою очередь, имеет простую и сложную структуру проявлений. Присутствие в жизни каждого человека разных сочетаний данных уровней формирует его жизненный стиль, предпочтения, приоритеты, которые со временем приобретают стереотипный, повторяющийся характер, закрепляясь в устойчивых чертах жизненной стратегии. Следовательно, жизненная стратегия, вследствие включения в себя способности противостоять обстоятельствам и последовательно достигать намеченное, включает в себя качество жизнестойкости.

Формирование стратегии жизнестойкости происходит под влиянием различных факторов на структуру личности и организацию деятельности по согласованию ожидаемых и реальных результатов действий индивида, учитывающего в своих действиях ресурсы, имеющиеся у самого субъекта и общества в целом.

Реакция на затруднения имеет три принципиально разных способа реагирования: непринятие, сопротивление, агрессия на препятствие; приспособление к ситуации, адаптирование за счет отказа от желаемого, минимизация ожиданий; осмысление, преобразование ситуации с ростом собственных жизненных ресурсов.

Данные реакции закрепляются в соответствующих стратегиях жизнестойкости дезадаптивно-преодолевающей (озлобленность, неудовлетворенность), адаптивноприспособительной (минимизация потребностей, ограничения, поиск лучшего в худшем), дезадаптивно-избегающей (смирение, подавление жизненных сил) и преобразующе-развивающей (принятие ситуации, осознание и поиск конструктивного решения) стратегиях.

Параметрами, фиксирующими модель выявления стратегий жизнестойкости пожилых людей, являются индикаторы, чувствительные к субъективным переживаниям, учитывающим практики организации жизненного пространства, оптимальные для данного периода онтогенеза. Были выделены следующие индикаторы: удовлетворенность жизнью; оценка собственной роли в формировании благоприятных условий жизни, в том числе в сравнении со сверстниками; вовлеченность в социальные связи; эмоциональные переживания; самоэффективность; оценка будущего.

Результаты опроса 2017 г. показали, что своей жизнью удовлетворены 83,8 \% респондентов, из них $27 \%$ - полностью удовлетворены; полностью не удовлетворены своей жизнью $2,3 \%$ и скорее не удовлетворены - 9,8 \%. Процент респондентов, разочарованных в жизни, составил всего 4,3\%. 75,5 \% от числа опрошенных в случае, если здоровье ограничивает им социальную жизнь, продолжают быть активными и компенсируют это тем, что они могут делать, только 5,8 \% - ничего не предпринимают. Исходя из ранее установленной зависимости в исследованиях С. Мадди между уровнем удовлетворенности жизнью и жизнестойкостью можно утверждать, что для подавляю- 
щего большинства участников опроса характерен высокий уровень жизнестойкости, соответствующий преобразующе-развивающей стратегии.

$91 \%$ участников опроса считали себя активно живущими, действующими и самодостаточными в жизни, которой они сами распоряжаются. Только $9 \%$ респондентов считали себя выброшенными из жизни, остальные 89 \% полагали, что у них есть время делать то, от чего они действительно получают удовольствие, $11 \%$ так не считали. Все опрошенные, имеющие такое мнение, представлены возрастной группой «71 год и старше», имеющие доход ниже шести тысяч рублей в месяц.

Оценка собственной жизни пожилым человеком в разных ее проявлениях выражает уровень субъективно значимого для него благополучия. Собой были удовлетворены 86,6 \% респондентов, не удовлетворены - 9,1\%. Оценивая себя в сравнении с другими, $44,8 \%$ считали себя более удачливыми, $15 \%$ - сомневались в своей удачливости, считая себя не совсем удачливыми. 83,8 \% отметили, что делают полезные дела, которые ценятся другими, 16,2 \% - полагали, что то, что они делают, другими не ценится.

Очень важным является факт отсутствия культурной изолированности в восприятии происходящего в жизни пожилого человека. На это указывает то, что большинство респондентов имели позитивную оценку ценности того, что ими делается в жизни. $75 \%$ респондентов отметили, что, то, что они делают в жизни, ценно и нужно другим, только 10,7 \% респондентов затруднились в ответе на данный вопрос и 14,3 \% считали, что это не ценится другими.

На вопрос «Чувствуете ли Вы себя выброшенными из жизни?» только 1,0 \% респондентов ответил: «Да, чувствую», 8,0 \% сомневаются в выборе ответа, но склоняются больше к тому, что чувствуют себя выброшенными из жизни. 91 \% считают, что живут полноценной жизнью. 62,3 \% никогда не чувствовали себя покинутыми и только 4,2 \% респондентов постоянно чувствуют себя покинутыми.

Были оценены социальные модусы изолированности и покинутости. Подавляющее большинство $(89,7 \%)$ участников опроса имели глубокие социальные связи, таковых не было лишь у 10,3 \%. 86,8 \% участников опроса никогда не чувствовали себя изолированными от других и лишь $2 \%$ чувствовали себя изолированными.

Степень удовлетворенности отношениями высокая. $79 \%$ респондентов отметили, что рядом с ними есть люди, которые по-настоящему понимают их, с которыми можно поговорить и к кому можно обратиться. 69 \% полностью удовлетворены оказываемой им помощью, если возникает в ней необходимость, и только 8,8 \% респондентов совсем не удовлетворены, поскольку близкие им не помогают.

Возраст не воспринимается как помеха для новых отношений и дружбы для $31,3 \%$ респондентов, которые считают, что найдут новых друзей, как только они этого захотят. 20,5 \% респондентов полагают, что в этом возрасте уже сложно находятся новые друзья и они уже не смогут, даже если этого захотят, найти новых друзей.

Отношения с другими положительно оцениваются большинством респондентов. 91,5 \% респондентов положительно оценили отношения с родственниками, 86 \% участников опроса - с друзьями и знакомыми, 77,3 \% - с соседями. Отрицательно отношения с выделенными группами значимых людей оценил только $1 \%$ респондентов.

Можно констатировать, что выявленная высокая степень удовлетворенности социальными связями у пожилых людей является важным основанием для позитивного жизненного настроя и отражает высокий уровень жизнестойкости.

Результаты опроса показали, что эмоциональный настрой у подавляющего числа респондентов связан с позитивными переживаниями. Была выявлена позитивная жизненная позиция у большинства респондентов. 71,8 \% респондентов принимают жизнь 
такой, какая она есть, и берут от жизни лучшее. Данная стратегия подтверждает хорошую адаптируемость пожилых людей к жизни в обществе, научившихся справляться с трудностями без сильных потрясений и отчаяния.

С тревогой и неуверенностью воспринимают будущее $19,8 \%$ респондентов, $3,3 \%$ - со страхом и отчаянием, большинство же (75 \%) настроены позитивно. Одни из них, а это 45\%, воспринимают его спокойно, без особых ожиданий, и $30 \%$ участников опроса - с надеждой и оптимизмом.

Процент пожилых людей, переживающих чувство уныния, в группе оценивающих позитивно перспективы будущего составил всего лишь 24,6 \%, из них только 1,7 \% респондентов испытывают данное чувство постоянно.

В группе пожилых людей, воспринимающих будущее негативно, уныние на момент опроса испытывали $63,2 \%$ опрошенных, в том числе постоянно испытывали уныние $15,8 \%$.

За последний год часто испытывали счастье 55 \% респондентов, иногда чувствовали себя счастливыми 26,5 \%. Общая совокупность испытывающих счастье пожилых людей - участников опроса - в 2017 г. составила 94,2 \%. Показательным является то, что только 5,8 \% от общего числа респондентов испытывали счастье крайне редко.

Полученные результаты в ходе проведенного нами опроса совпадают с результатами, ранее установленными другими исследователями. Согласно исследованиям L.L. Carstensen и соавторов [13-15], старость характеризуется существенным улучшением в регуляции эмоций, увеличением удовлетворенности межличностными отношениями и сохранением психологического благополучия.

Сохранность самоконтроля, чувство уверенности в способности распоряжаться своей судьбой являются важным фактором, определяющим уровень субъективного благополучия и, соответственно, уровень жизнестойкости. 80 \% участников опроса отметили, что не нуждаются в регулярной помощи в повседневных делах, в том числе $65 \%$ редко обращается за помощью, предпочитая справляться с трудностями за счет собственных ресурсов.

Для большинства участников опроса характерен высокий жизненный тонус. Удовлетворение от того, что у них получается все, что они делают, испытывают почти каждый день $67,5 \%$ и 24,3\% не могут этого сказать о себе. На вопрос «Как часто за последнюю неделю Вы ощущали прилив сил и энергии?» 52,0 \% указали на все или почти все время в течение недели, 37,0 \% респондентов чувствовали прилив сил и энергии меньшую часть времени в течение недели и 11,0 \% участников опроса никогда или почти никогда в течение недели не чувствовали прилив сил и энергии. Выявление связи отсутствия сил и энергии с эмоциональным настроем показал, что для данной группы респондентов характерны тревога и неуверенность относительно будущего, чувство одиночества и уныния.

$67,5 \%$ респондентов указали, что в жизни есть многое, в чем они сильны, $16 \%$ полагают, что в их жизни этого нет. 85,8 \% сами решают, как им жить и $11 \%$ отметили, что решения принимаются другими.

В ходе исследования была выявлена зависимость между оцениванием здоровья и позитивным восприятием будущего. Среди оптимистично настроенных респондентов в 1,7 раза было больше тех, кто оценивал свое здоровье как хорошее или очень хорошее. И наоборот, в группе пессимистично настроенных респондентов, расценивающих свое здоровье как плохое, было больше в 7,5 раз. 


\section{Выводы}

Проведение кластерного анализа выявило наличие у пожилых людей три типа жизненной стратегии: активная, пассивная и ситуативно-адаптивная. Активная жизненная стратегия характеризуется высокой степенью осмысленности жизни, способностью к восприятию собственной жизни как важной для человека и других людей, высоким уровнем ответственности за то, что человек делает. Данный тип стратегии соответствует преобразующе-развивающей стратегии жизнестойкости и является преобладающим у пожилых людей.

Пассивная жизненная стратегия характеризуется отрицанием собственной возможности оказывать влияние на происходящие события и неудовлетворенностью жизнью в целом, соответствует дезадаптивно-избегающей (смирение, подавление жизненных сил, ощущение собственной беспомощности) стратегии жизнестойкости. Данная стратегия свойственна небольшому числу респондентов и позволяет сделать вывод относительно того, что период выхода на пенсию не должен восприниматься как остановленное развитие, путь «в никуда».

Ситуативно-адаптивный тип жизненной стратегии направлен на реализацию жизненных целей в конкретной ситуации, является адаптивно-приспособительной стратегией жизнестойкости. Данному типу стратегии соответствует средняя степень выраженности осмысленности жизни, человек в целом воспринимает свою жизнь эмоционально насыщенной, интересной, удовлетворен своим жизненным путем, готов самостоятельно противостоять жизненным трудностям.

В целом была подтверждена гипотеза относительно связи жизнестойкости в пожилом возрасте с качеством субъективного благополучия человека. Анализ социологических данных позволил выявить тенденцию, которая проявляется в прямой зависимости уровня жизнестойкости и субъективного благополучия и согласуется с концепцией жизнестойкости С. Мадди.

Исследование выполнено за счет гранта Российского научного фонда (проект № 19-18-00282).

\section{СПИСОК ЛИТЕРАТУРЫ}

1. Мадди С. Теории личности: сравнительный анализ. - СПб.: Речь, 2002. - 539 с.

2. Аргайл М. Психология счастья. - СПб.: Питер, 2003. - 271 с.

3. Франкл В. Человек в поисках смысла / под ред. Л.Я. Гозмана и Д.А. Леонтьева. - М.: Прогресс, 1990. - 368 c.

4. Борисов Г.И. Жизнестойкость людей пожилого возраста как фактор продолжения профессиональной деятельности // Эффективность личности, группы и организации: проблемы, достижения и перспективы: материалы Всероссийской научно-практической конференции. - М.: Кредо, 2017. - С. $23-25$.

5. Левицкая Т.Е., Богомаз С.А. Особенности картины мира человека с высокой жизнестойкостью // Гуманитарные основания развития региона с высоким инновационным потенциалом: глобализация, идентификация, миграция. - Томск: Изд-во ТГУ: Дельтаплан, 2007. - С. 53-56.

6. Зеер Э.Ф., Сыманюк Э.Э., Борисов Г.И. Психологические факторы жизнеспособности человека позднего возраста // Известия Российской академии образования. - 2017. - № 1 (41). - С. 86-97.

7. Кольман С.Е., Курилович М.А. Проблема жизнестойкости в пенсионном возрасте // Экономика и социум. - 2016. - № 12-3 (31). - С. 170-173.

8. Купченко В.Е., Елькина Е.В. Особенности жизнестойкости личностей с различным типом жизненной стратегии // Вестник Омского университета. Серия «Психология». - 2010. - № 1. - С. 4-9.

9. Супрунова О.В. Особенности субъективного благополучия и жизнестойкости в контексте личностных свойств // Высшее образование сегодня. - 2016. - №6. - С. 55-57.

10. Бородкина Е.В. Жизнестойкость как фактор субъективного благополучия // Актуальные вопросы современной психологии и педагогики: Сборник докладов международной научной заочной конференции. - Липецк: Де-факто, 2009. - С. 12-15. 
11. Мадди С. Смыслообразование в процессе принятия решений // Психологический журнал. - 2005. № 6. - С. 87-101.

12. Эдкинд Д. Эриксон Э. и восемь стадий человеческой жизни. - М.: Ин-т психологии РАН, 2013. - 160 с.

13. Carstensen L.L., Charles S.T. Emotion in the second half of life // Current Directions in Psychological Science. - 1998. - V. 7. - № 5. - P. 144-149.

14. Emotion and aging / M. Pasupathi, L.L. Carstensen, S. Turk-Charles, J. Tsai // Encyclopedia of mental health. - 1998. - V. 2. - P. 91-101.

15. Carstensen L.L. et al. Emotional experience in everyday life across the adult life span // Journal of personality and social psychology. - 2000. - V. 79. - № 4. - P. 644-655. URL: https://doi.org/10.1037/00223514.79.4.644 (дата обращения 15.10.2020).

Поступила 27.10.2020 г. 
UDC 316.346.32-053.9

\title{
STRATEGIES FOR THE RESILIENCE OF OLDER PEOPLE
}

\author{
Lubov I. Ivankina, \\ ivankina@tpu.ru \\ Ekaterina A. Anikina, \\ anikinaea@tpu.ru \\ Elena I. Klemasheva, \\ eik15@tpu.ru \\ Casati Fabio, \\ casati@tpu.ru
}

\begin{abstract}
National Research Tomsk Polytechnic University, 30, Lenin avenue, Tomsk, 634050, Russia.
\end{abstract}

Lubov I. Ivankina, Dr. Sc., professor, National Research Tomsk Polytechnic University.

Ekaterina A. Anikina, Cand. Sc., associate professor, National Research Tomsk Polytechnic University.

Elena I. Klemasheva, Cand. Sc., associate professor, National Research Tomsk Polytechnic University.

Casati Fabio, PhD, leading research scientist, National Research Tomsk Polytechnic University.

The relevance of the problem of older people resilience is caused by scientific and practical interest in finding models and ways to develop human compensatory capabilities at the stage of late ontogenesis. The modern approach to aging changes the pessimistic view on this period of human life as the final, associated with the withering and fading of vital functions, to the optimistic one, considering the period of late ontogenesis as a stage of continuing human development. The aim of the work is to identify the features and main types of strategies for the resilience of older people. In accordance with the research problem, the analysis of data from a sociological survey was carried out, which allowed us to identify the level of resilience based on indicators that are important for measuring and monitoring the main aspects of the well-being of older peoplelife satisfaction, involvement in social relations, happiness, confidence in the future. The research methodology is based on the operationalization of the concepts of "resilience» and «inequality», which made it possible to identify the sources of inequality in the aspect of mental practices - thoughts, beliefs, ideas about their own role in ensuring well-being. This approach is primarily due to the psychological nature of the phenomenon of resilience as a special experience that guarantees a person the ability to act in complex, uncertain situations as effectively as possible. The result of the study. The parameters of differentiation of resilience strategies of elderly people are justified, the specifics and types of resilience strategies in the period of late ontogenesis are revealed. Analysis of data from a sociological survey of older people revealed the resources of resilience, which include the well-being of family and loved ones and the ability to make decisions and implement plans. The quality of social subjectivity was revealed, which prevents the maintenance of the quality of life and the increase of the resilience of people in old age; this is the shifting of responsibility onto others with the entrenched position «you owe me».

Key words: Resilience, older people, life strategy, resilience strategy, life position, subjective well-being.

\section{REFERENCES}

1. Maddi S. Teorii lichnosti: sravnitelny analiz [Personality theories: a comparative analysis]. St. Petersburg, Rech Publ., 2002. 539 p. 
2. Argayl M. Psikhologiya schastya [The psychology of happiness]. St. Petersburg, Piter Publ., 2003. 271 p.

3. Frankl V. Chelovek v poiskakh smysla [Man in Search of Meaning]. Moscow, Progress Publ., 1990. 368 p.

4. Borisov G.I. Zhiznestoykost lyudey pozhilogo vozrasta kak faktor prodolzheniya professionalnoy deyatelnosti [The resilience of the elderly as a factor in continuing professional activity]. Materialy Vserossiyskoy nauchno-prakticheskoy konferentsii. Effektivnost lichnosti, gruppy i organizatsii: problemy, dostizheniya i perspektivy. Moscow, Kredo Publ., 2017. pp. 23-25.

5. Levitskaya T.E. Osobennosti kartiny mira cheloveka s vysokoy zhiznestoykostyu [Features of the picture of the world of a person with high resilience]. Gumanitarnye osnovaniya razvitiya regiona $s$ vysokim innovatsionnym potentsialom: globalizatsiya, identifikatsiya, migratsiya. Tomsk, TGU Publ., Deltaplan Publ., 2007. pp. 53-56.

6. Zeer E.F., Symanyuk E.E., Borisov G.I. Psikhologicheskie faktory zhiznesposobnosti cheloveka pozdnego vozrasta [Psychological factors of the viability of a person of late age]. Izvestiya Rossiyskoy akademii obrazovaniya, 2017, no. 1 (41), pp. 86-97.

7. Kolman S.E., Kurilovich M.A. Problema zhiznestoykosti v pensionnom vozraste [The problem of resilience at retirement age]. Ekonomika i sotsium, 2016, no. 12-3 (31), pp. 170-173.

8. Kupchenko V.E., Elkina E.V. Osobennosti zhiznestoykosti lichnostey s razlichnym tipom zhiznennoy strategii [Features of the resilience of individuals with different types of life strategies]. Vestnik Omskogo universiteta. Seriya «Psikhologiya», 2010, no. 1, pp. 4-9.

9. Suprunova O.V. Osobennosti subektivnogo blagopoluchiya i zhiznestoykosti v kontekste lichnostnykh svoystv [Features of subjective well-being and resilience in the context of personal properties]. Vysshee obrazovanie segodnya, 2016, no. 6, pp. 55-57.

10. Borodkina E.V. Zhiznestoykost kak faktor subektivnogo blagopoluchiya [Resilience as a factor in subjective well-being]. Sbornik dokladov mezhdunarodnoy nauchnoy zaochnoy konferentsii. Aktualnye voprosy sovremennoy psikhologii i pedagogiki. Lipetsk, De-fakto, 2009. pp. 12-15.

11. Maddi S. Smysloobrazovanie v protsesse prinyatiya resheniy [Meaning formation in the decision-making process]. Psikhologicheskiy zhurnal, 2005, no. 6, pp. 87-101.

12. Edkind D. Erikson E. $i$ vosem stadiy chelovecheskoy zhizni [Erickson E. and the eight stages of human life]. Moscow, In-t psikhologii RAN Publ., 2013. 160 p.

13. Carstensen L.L., Charles S.T. Emotion in the second half of life. Current Directions in Psychological Science, 1998, vol. 7, no. 5, pp. 144-149.

14. Pasupathi M., Carstensen L.L., Turk-Charles S., Tsai J. Emotion and aging. Encyclopedia of mental health, 1998, vol. 2, pp. 91-101.

15. Carstensen L.L. Emotional experience in everyday life across the adult life span. Journal of personality and social psychology, 2000, vol. 79, no. 4, pp. 644-655. Available at: https://doi.org/10.1037/00223514.79.4.644 (accessed 15 October 2020).

Received: 27 October 2020. 